Article

\title{
Study on Inclusions Distribution and Cyclic Fatigue Performance of Gear Steel 18CrNiMo7-6 Forging
}

\author{
Min Wang ${ }^{1, *}$, Wei Xiao ${ }^{1}$, Peng Gan ${ }^{2}$, Chao Gu ${ }^{1}$ and Yan-Ping Bao ${ }^{1}$ \\ 1 State Key Laboratory of Advanced Metallurgy, University of Science and Technology Beijing, Beijing 100083, \\ China; emmy.xiaowei@hotmail.com (W.X.); guchao@ustb.edu.cn (C.G.); baoyp@ustb.edu.cn (Y.-P.B.) \\ 2 CISDI Engineering Co. Ltd., Chongqing 400013, China; kery_gp@126.com \\ * Correspondence: wangmin@ustb.edu.cn
}

Received: 12 December 2019; Accepted: 25 January 2020; Published: 31 January 2020

\begin{abstract}
The three-dimensional morphologies of inclusions in gear steel 18CrNiMo7-6 forging were investigated by a non-destructive extraction method, and the cleanliness of radial positions was analyzed, mainly including the variation of total oxygen content and the distribution of size and quantity of inclusions. In addition, fatigue performance was tested using an ultrasonic fatigue machine to investigate the fatigue characteristics of the steel. The results show that the quantity density of inclusions per unit volume in gear steel $18 \mathrm{CrNiMo}-6$ decreases exponentially with increasing size, oxide inclusions with a size less than $8 \mu \mathrm{m}$ account for more than $90 \%$, while sulfide inclusions account for more than $85 \%$. The average value of the oxygen content can reflect the level of inclusions that were evenly distributed in the molten steel, and the accumulative total oxygen content increases significantly with increasing inclusion size. The fatigue specimen failed after the stress exceeded the critical value, and fatigue failure hardly occurred when the stress was below the critical value. Meanwhile, large-sized nondeformable inclusions such as $\mathrm{Al}_{2} \mathrm{O}_{3}-\mathrm{CaO}$ in gear steel $18 \mathrm{CrNiMo7}-6$ are closely related to fatigue failure. It is recommended that the area from the center to the $1 / 2$ radius with low cleanliness should be avoided, while the area from the $3 / 4$ radius to the edge with high cleanliness should be selected during the machining of the gear.
\end{abstract}

Keywords: gear steel; inclusions distribution; cyclic fatigue; three-dimensional morphology

\section{Introduction}

As a necessary transmission part of mechanical equipment, different kinds of high-alloy gears have been widely applied and popularized in industrial production to meet the requirements of aerospace, metallurgical manufacturing, automobile production, mining, lifting transportation and building materials machinery, etc. [1,2]. Among them, the application of $18 \mathrm{CrNiMo7-6}$ according to the standard of DIN (German Institute for Standardization) in Germany has become increasingly widespread with the expansion of high-alloy gear steel production, and the predecessor of this steel is 17CrNiMo6 gear steel [2].

Carburizing gear steel $18 \mathrm{CrNiMo7-6}$ is a surface-hardened steel with high strength, high toughness and high hardenability, which is widely used in mining, transportation, locomotive traction, lifting and internal power, and other industrial fields [3]. JFE steel corporation has developed a new carburizing steel that realizes an intermediate heat treatment-free process (omission of annealing before cold forging and normalizing before carburizing) in the manufacture of carburized gear parts, which makes it possible to reduce the cost and improve the fatigue life of gear parts [4]. The mechanical properties in relation to fracture toughness are often governed by the independent or conjoint influences of the following [5,6]: (a) chemical composition, (b) steel cleanness including inclusions and harmful elements in the matrix, (c) processing history and development of intrinsic microstructural features, (d) service 
conditions and circumstances of the components including loading-rate, working temperature and the presence of constraints at the crack tip. High surface quality was the essential condition to meet the requirement of harsh working conditions of the gear steel, so it is necessary to control the steel cleanliness and inclusions characterization, including morphologies, size, number and distribution, for guaranteeing the fatigue property of the steel [7-10]. An et al. [11] studied the inclusions evolution of gear steel in the refining process, and discovered the formation mechanism of oxide-sulfide duplex inclusion. Dong et al. $[12,13]$ found that the large inclusions in gear steel are mainly external during the refining process. Nordin et al. [14] summarized that there were three main factors from shot peening that influence the fatigue life of gear steel: residual stresses, microstructure and surface roughness. However, previous studies did not cover the in-depth study of the relationship between inclusions distribution and the fatigue property of final products of gear steel. It is necessary to discover an optimum method to evaluate the fatigue life under various manufacturing conditions because of the long duration of fatigue life of high-quality steel. Recently, the ultra-sonic method has been one of the available methods for the testing of cracks and fatigue life of steel.

In this paper, gear steel $18 \mathrm{CrNiMo7}-6$ forging is studied. The three-dimensional morphologies of inclusions in the gear steel were determined by the non-destructive extraction method of inclusions, and the variation of total oxygen content as well as the size, quantity and composition of inclusions in different radial positions were also investigated to clarify the distribution of the cleanliness of the gear steel and the area where the inclusions accumulate. In addition, fatigue tests were also carried out using an ultrasonic fatigue testing machine to investigate the fatigue characteristics of the steel. This provides theoretical guidance for avoiding areas of poor cleanliness in follow-up processing, thereby laying the foundation for further improving the quality of gears [15].

\section{Experimental Materials and Methods}

\subsection{Experimental Materials}

The smelting technological process of gear steel $18 \mathrm{CrNiMo7}-6$ is as follows: $\mathrm{EAF} \rightarrow \mathrm{LF} \rightarrow \mathrm{VD} \rightarrow \mathrm{Ingot}$ cast. The ingot was forged into a piece for the gear process. The following steps are required for the forge piece to be processed into a gear: normalizing $\rightarrow$ rough turning $\rightarrow$ quenching and tempering $\rightarrow$ finish turning $\rightarrow$ cutting teeth $\rightarrow$ carburizing, quenching and tempering $\rightarrow$ making spline $\rightarrow$ gear grinding. A forge piece with a diameter of $280 \mathrm{~mm}$ was prepared before cutting teeth for the experiment. The chemical composition of the steel is listed in Table 1.

Table 1. Chemical composition of gear steel 18CrNiMo7-6 (wt \%).

\begin{tabular}{cccccccccc}
\hline $\mathbf{C}$ & $\mathbf{S i}$ & $\mathbf{M n}$ & $\mathbf{P}$ & $\mathbf{S}$ & $\mathbf{C r}$ & $\mathbf{N i}$ & $\mathbf{M o}$ & $\mathbf{A l}$ & $\mathbf{M g}$ \\
\hline $0.15-0.20$ & $\leq 0.40$ & $0.50-0.90$ & $\leq 0.02$ & $0.01-0.02$ & $1.50-1.80$ & $1.40-1.70$ & $0.25-0.35$ & 0.03 & 0.0003 \\
\hline
\end{tabular}

Different types of samples as described in Figure 1 were prepared for total oxygen testing, inclusions extraction, inclusions quantitative analysis and cyclic fatigue performance evaluation. Fourteen rod-like specimens with sizes of $\phi 10 \mathrm{~mm} \times 80 \mathrm{~mm}$ were machined along the edge of the forging ingot for the fatigue performance test. Cubic specimens with sizes of $15 \mathrm{~mm} \times 15 \mathrm{~mm} \times 15 \mathrm{~mm}$ were machined in the locations of center, $1 / 2$ radius, $3 / 4$ radius, and outer edge of the forge piece for inclusions quantitative analysis by automatic scanning technology. Rod-like specimens for total oxygen testing were cut from the center, $1 / 4$ radius, $1 / 2$ radius, $3 / 4$ radius and outer edge of the forge piece. 


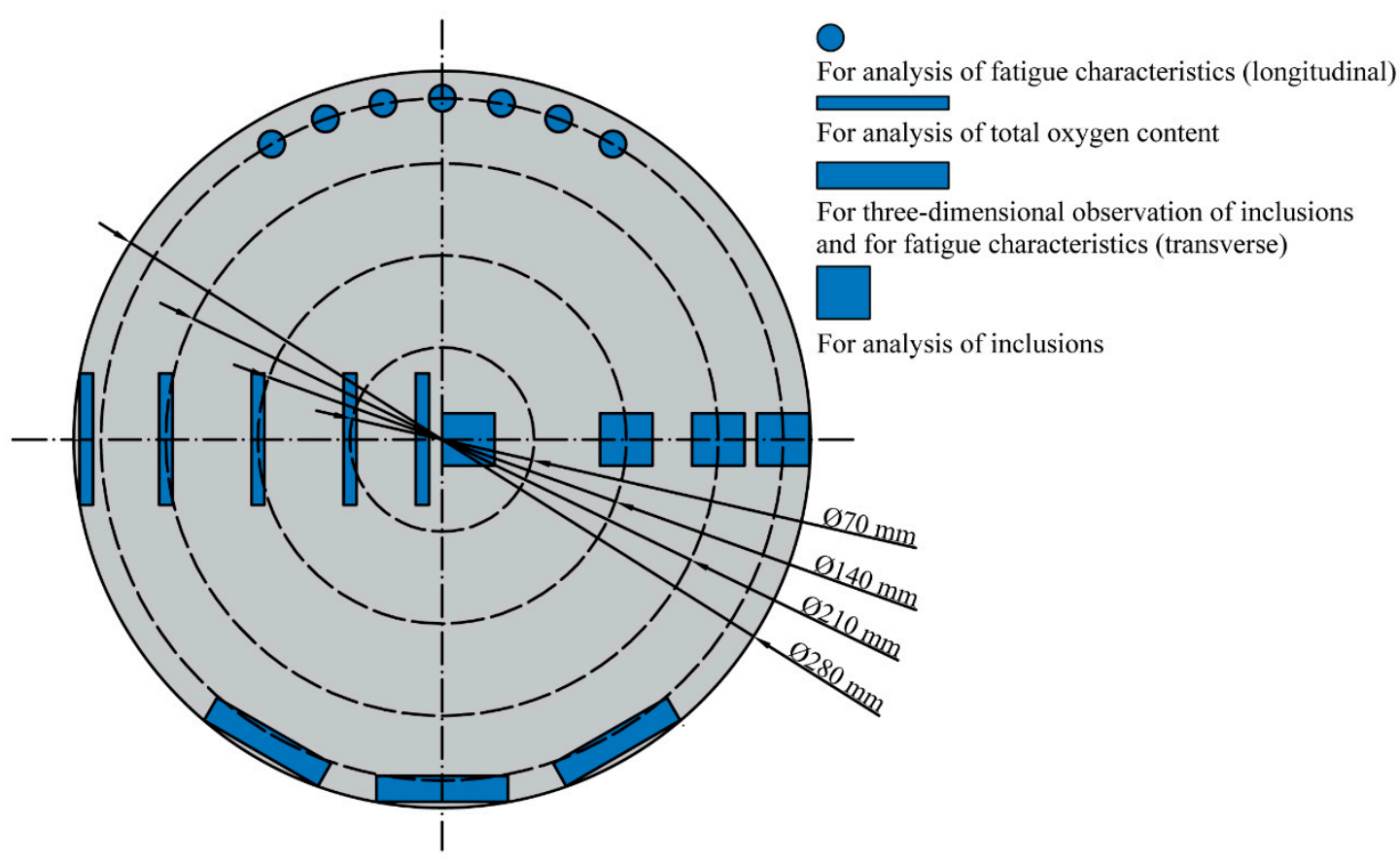

Figure 1. Sampling preparation of 18CrNiMo7-6 forge piece.

\subsection{Experimental Methods}

The total oxygen in radial positions of the gear steel was analyzed using the infrared absorption method. Inclusions were extracted from the steel matrix using a non-destructive method with aqueous solution (deionized water + potassium chloride + citric acid) and collected on the conductive adhesive after separating with a filter membrane to observe the three-dimensional morphologies of the inclusions under a scanning electron microscope [16]. The Oxford INCA System (EVO18, Zeiss, Oberkochen, Germany) was adopted to analyze the sizes, shapes and chemical compositions of inclusions on a scanning area of $53.5 \mathrm{~mm}^{2}$. Cycle fatigue performance was tested using an ultrasonic fatigue system (CSPL-20, Chengdu MCT Technology Co. Ltd., Chengdu, China) with $20 \mathrm{KHz}$ frequency under fully reversed tension-compression $(\mathrm{R}=-1)$ loading condition. The stability diagram of the Fe-Si-Al-Mg-O system inclusions was calculated in liquid steel at $1600{ }^{\circ} \mathrm{C}$ by using FactSage 7.2 (The Integrated Thermodynamic Databank System, GTT-Technologies, Herzogenrath, Germany).

\section{Results and Discussion}

\subsection{Morphological Characteristics of Inclusions in the Gear Steel}

As showed in Figure 2, four different types of inclusions, namely, $\mathrm{MnS}, \mathrm{Al}_{2} \mathrm{O}_{3}, \mathrm{Al}_{2} \mathrm{O}_{3}-\mathrm{MgO}$, and $\mathrm{Al}_{2} \mathrm{O}_{3}-\mathrm{SiO}_{2}$, are found on the forging cross-section after the treatment of non-destructive extraction.

The morphology of $\mathrm{Al}_{2} \mathrm{O}_{3}$ is mostly massive, with a diameter of 5-15 $\mu \mathrm{m}$, and it is a common deoxidization product in the steelmaking process with a large quantity. The $\mathrm{Al}_{2} \mathrm{O}_{3}-\mathrm{MgO}$ spinel is similar to the $\mathrm{Al}_{2} \mathrm{O}_{3}$ inclusions with small clusters, and both of them are harmful to the fatigue life of steel due to the high hardness and low deformability [17-19]. Additionally, some spherical and spheroidal silicates, which possessed relatively low hardness and good formability compared with the $\mathrm{Al}_{2} \mathrm{O}_{3}$ and spinel, were also found.

$\mathrm{MnS}$ inclusions in the steel matrix are mostly elongated or spindle-shaped after the rolling process due to their good plasticity. It has been pointed out that spindle MnS inclusions are beneficial to the mechanical properties and free-cutting properties of steel, but have almost no effect on the quality of steel [20]. 

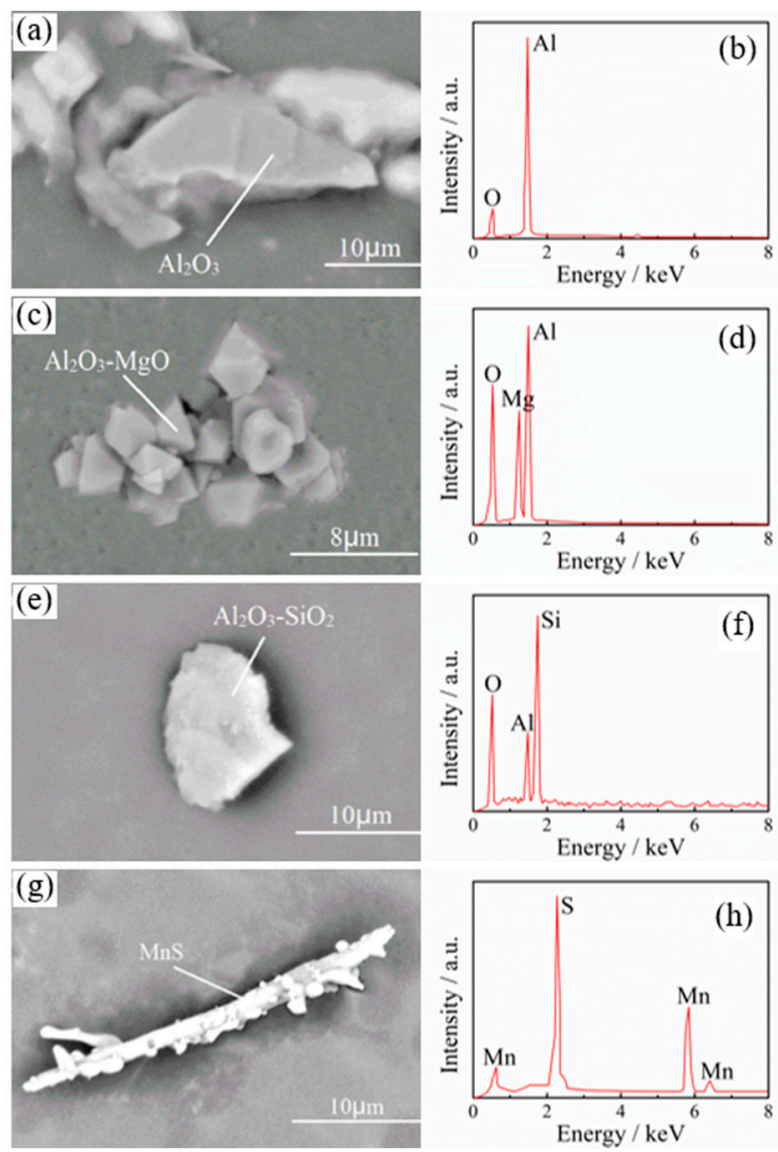

Figure 2. Three-dimensional morphologies, (a) $\mathrm{Al}_{2} \mathrm{O}_{3}$, (c) $\mathrm{Al}_{2} \mathrm{O}_{3}-\mathrm{MgO}$, (e) $\mathrm{Al}_{2} \mathrm{O}_{3}-\mathrm{SiO}_{2}$, and (g) $\mathrm{MnS}$; and compositions of inclusions, (b) $\mathrm{Al}_{2} \mathrm{O}_{3}$, (d) $\mathrm{Al}_{2} \mathrm{O}_{3}-\mathrm{MgO}$, (f) $\mathrm{Al}_{2} \mathrm{O}_{3}-\mathrm{SiO}_{2}$, and (h) $\mathrm{MnS}$.

In Figure 3, inclusion stability diagrams of the Fe-Si-Mg-O system (a) and the Fe-Si -O system (b) at $1600{ }^{\circ} \mathrm{C}$ were calculated. It can be seen that $\mathrm{Al}_{2} \mathrm{O}_{3}-\mathrm{MgO}$ (spinel) and $\mathrm{Al}_{2} \mathrm{O}_{3}$ can be formed and exist stably in molten steel after the deoxidization. The formation time of sulfide inclusions is later than that of oxide inclusions, most of which are formed during the solidification of molten steel. Therefore, the oxide inclusions can easily provide nucleation conditions for the formation of sulfide inclusions. It has been pointed out that the MnS inclusion can almost precipitate [21] on any kind of oxide when $w(\mathrm{~S})$ is more than $0.01 \%$. The content of $\mathrm{S}$ in the forging of gear steel $18 \mathrm{CrNiMo}-6$ is more than $0.01 \%$, resulting in complex inclusions with oxide inclusions as the core and MnS forming wraps around the periphery. Due to the better plasticity and softer texture of $\mathrm{MnS}$ inclusions, the harmful effects of $\mathrm{Al}_{2} \mathrm{O}_{3}, \mathrm{Al}_{2} \mathrm{O}_{3}-\mathrm{MgO}$, silicate and other oxide inclusions on the steel matrix can be reduced to a certain extent. Moreover, there is a small amount of high-melting CaS inclusions in gear steel 18CrNiMo7-6. These inclusions are also easily deformed during rolling, and the three-dimensional morphology is basically in a regular strip shape. The formation of such inclusions is caused by excessive calcium content during the refining process $[22,23]$. 

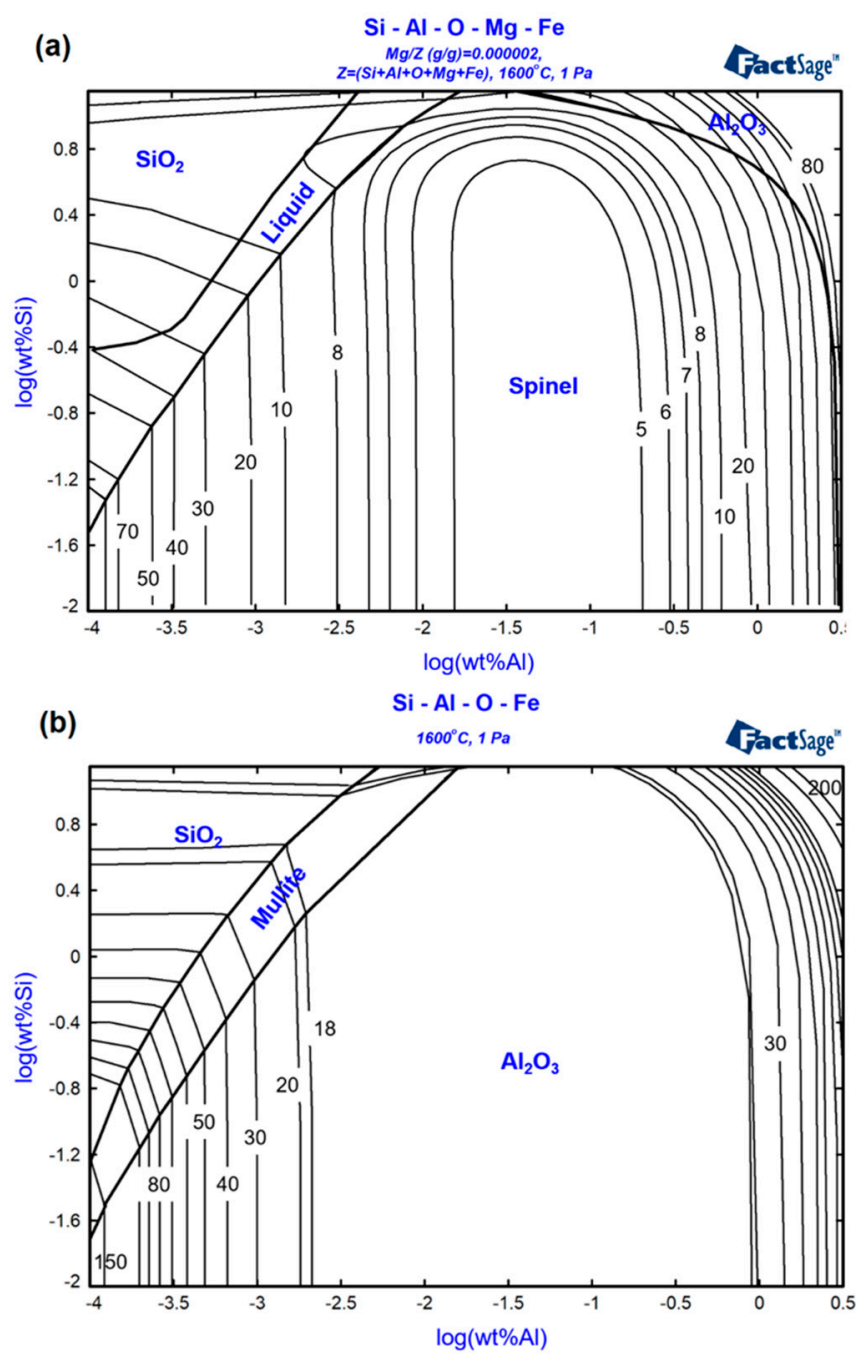

Figure 3. Calculated inclusion stability diagrams of the Fe-Si-Mg-O system (a) and the Fe-Si-O system (b) at $1600^{\circ} \mathrm{C}$.

\subsection{Distribution of Inclusions in Radial Directions}

The quantitative distribution of the main inclusions in the center, $1 / 2$ radius, $3 / 4$ radius and edge of the forging were analyzed using the Oxford INCA System. Four different types of oxide inclusions, mainly including $\mathrm{Al}_{2} \mathrm{O}_{3}-\mathrm{CaO}, \mathrm{Al}_{2} \mathrm{O}_{3}, \mathrm{Al}_{2} \mathrm{O}_{3}-\mathrm{MgO}$ and silicates, existed in the steel matrix. Figure $4 \mathrm{a}$ shows the distribution of $\mathrm{Al}_{2} \mathrm{O}_{3}-\mathrm{CaO}$ inclusions. The total amount of such inclusions is small, but a large proportion of such inclusions are distributed on the edge of the forge piece, which is very damaging for the working condition of the gear because this area is very close to the service face of the gear. Figure $4 \mathrm{~b}$ shows the size distribution of $\mathrm{Al}_{2} \mathrm{O}_{3}$ inclusions. The $\mathrm{Al}_{2} \mathrm{O}_{3}$ inclusions with sizes of $2-4 \mu \mathrm{m}$ occupy the largest proportion of $50.7 \%$. With increasing size, the proportion of inclusions decreases gradually. The largest proportions of inclusions with sizes below $4 \mu \mathrm{m}$ from the center to the edge reach $78.3 \%, 60.0 \%, 72.7 \%$ and $68.8 \%$, respectively. Large-sized inclusions above $10 \mu \mathrm{m}$ only appear at the location of the $1 / 2$ radius and account for $10 \%$ of the total. The sizes of $\mathrm{Al}_{2} \mathrm{O}_{3}-\mathrm{MgO}$ inclusions are all below $10 \mu \mathrm{m}$, and the number of $2-4 \mu \mathrm{m}$ reaches $59.6 \%$. The largest proportions of inclusions with sizes below $4 \mu \mathrm{m}$ from the center to the edge reach $100.0 \%, 90.9 \%, 73.3 \%$, and $80.0 \%$, respectively. Figure $4 \mathrm{~d}$ shows the size distribution of silicate inclusions, and large silicate inclusions with sizes above $10 \mu \mathrm{m}$ appear at the location of the $1 / 2$ radius, accounting for $44.4 \%$ of the total silicate inclusions. 


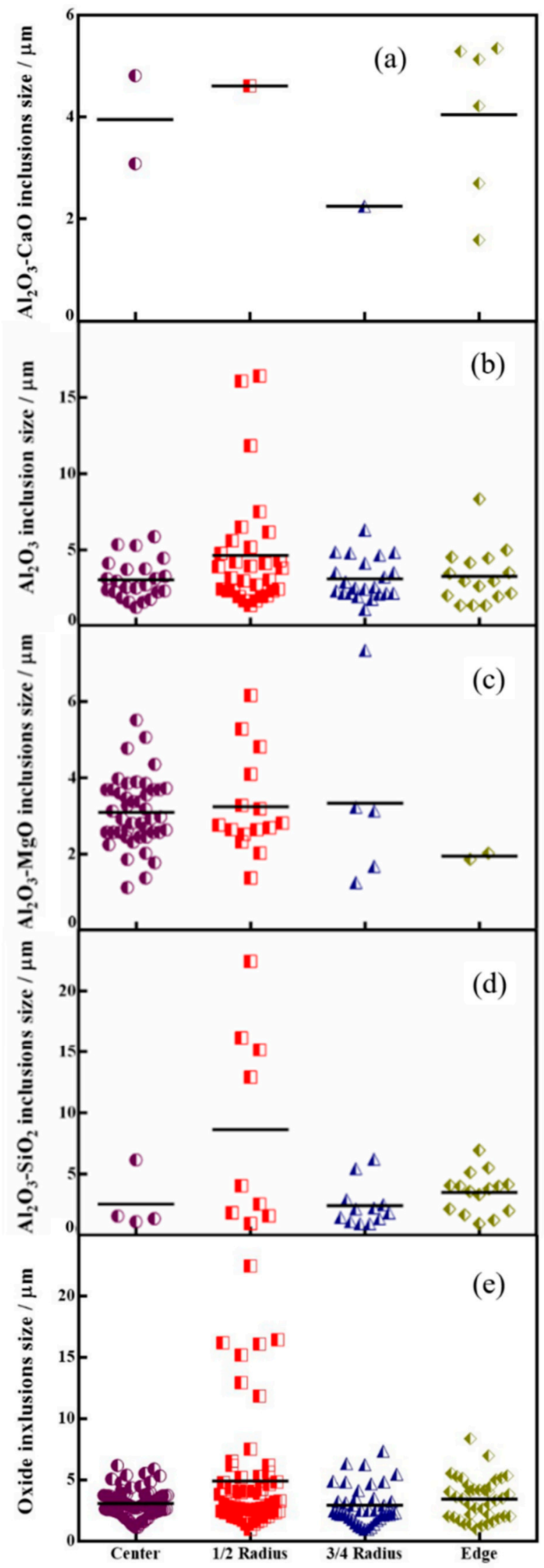

Figure 4. Size distribution of (a) $\mathrm{Al}_{2} \mathrm{O}_{3}-\mathrm{CaO}$, (b) $\mathrm{Al}_{2} \mathrm{O}_{3}$, (c) $\mathrm{Al}_{2} \mathrm{O}_{3}-\mathrm{MgO}$, (d) $\mathrm{Al}_{2} \mathrm{O}_{3}-\mathrm{SiO}_{2}$, and (e) all oxide inclusions at different locations. 
The relationship between the accumulative oxide density and the size in per unit volume is shown in Figure 5, indicating that the quantity of inclusions with a size less than $8 \mu \mathrm{m}$ accounts for more than $90 \%$. With increasing inclusion size, the quantity density tends to decrease. The quantity density of $\mathrm{Al}_{2} \mathrm{O}_{3}$ inclusions along the radius shows little change. The quantity densities of $\mathrm{Al}_{2} \mathrm{O}_{3}-\mathrm{MgO}$ and silicate inclusions reach the highest at $0.82 / \mathrm{mm}^{2}$ and $0.36 / \mathrm{mm}^{2}$, respectively.

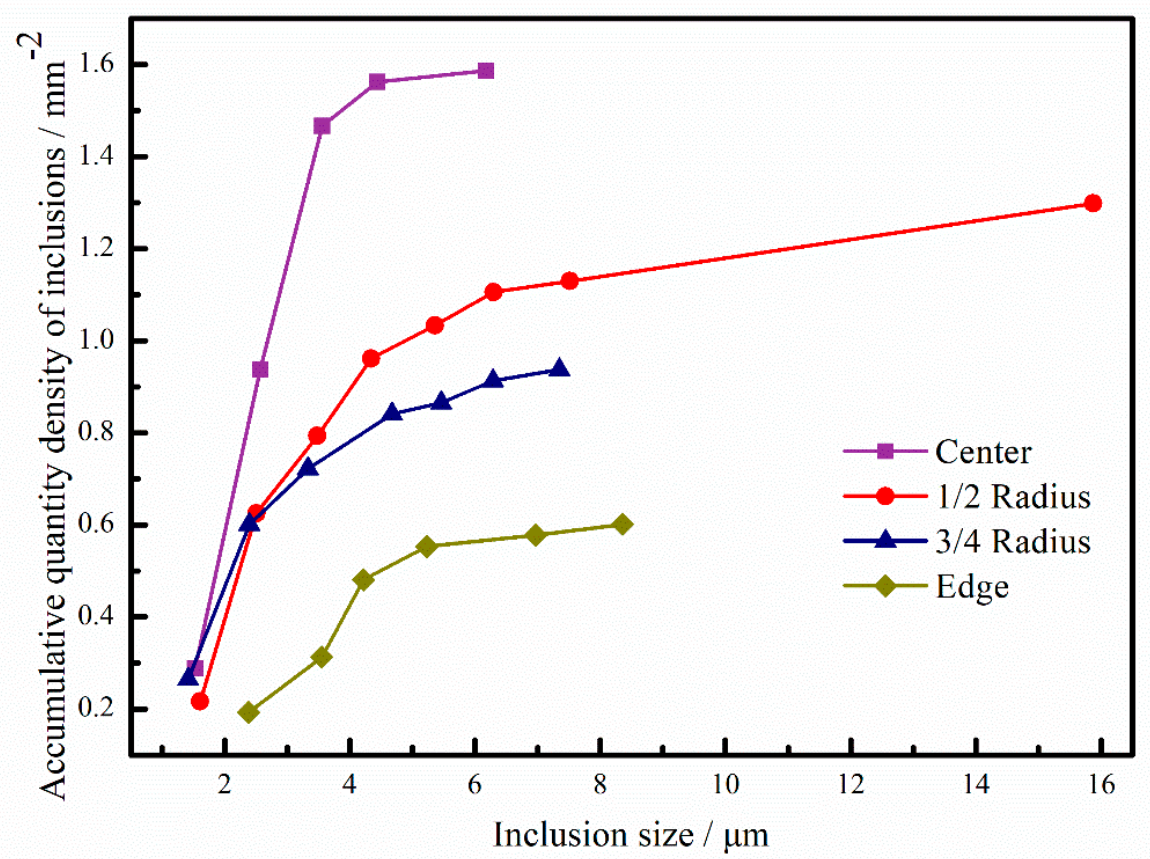

Figure 5. Accumulative quantity density of different sizes of oxide inclusions.

Figure 6 shows the size distribution of sulfide inclusions. The largest proportion of inclusions with sizes below $2 \mu \mathrm{m}$ reaches $50.5 \%$. From the center to the edge, the number of sulfide inclusions decreases gradually, and the average sizes increase slightly, which is due to the segregation of sulfur during the solidification. 


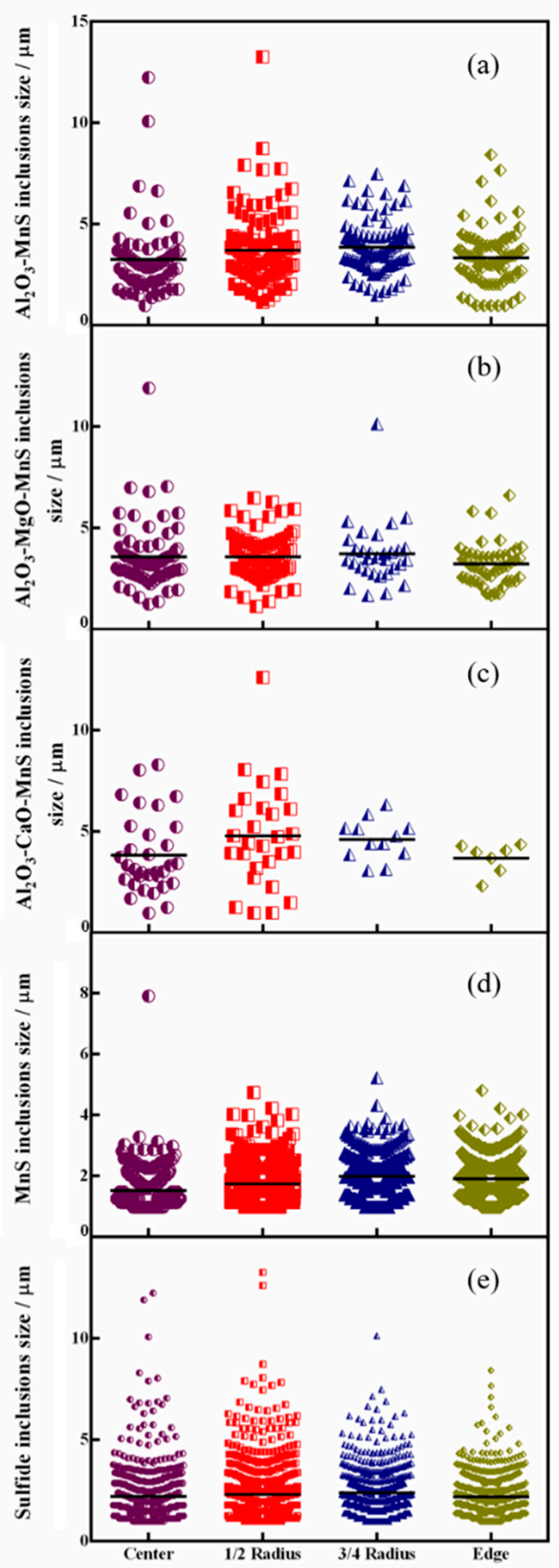

Figure 6. Size distribution of (a) $\mathrm{Al}_{2} \mathrm{O}_{3}-\mathrm{MnS}$, (b) $\mathrm{Al}_{2} \mathrm{O}_{3}-\mathrm{MgO}-\mathrm{MnS}$, (c) $\mathrm{Al}_{2} \mathrm{O}_{3}-\mathrm{CaO}-\mathrm{MnS}$, (d) $\mathrm{MnS}$, and (e) all sulfide inclusions at different locations.

Figure 7 shows the distribution of sulfide inclusions per unit volume. It is found that the quantity of inclusions decreases exponentially with increasing size. As can be seen from Figure 6, the quantity of sulfide inclusions with a size less than $8 \mu \mathrm{m}$ accounts for more than $85 \%$. 


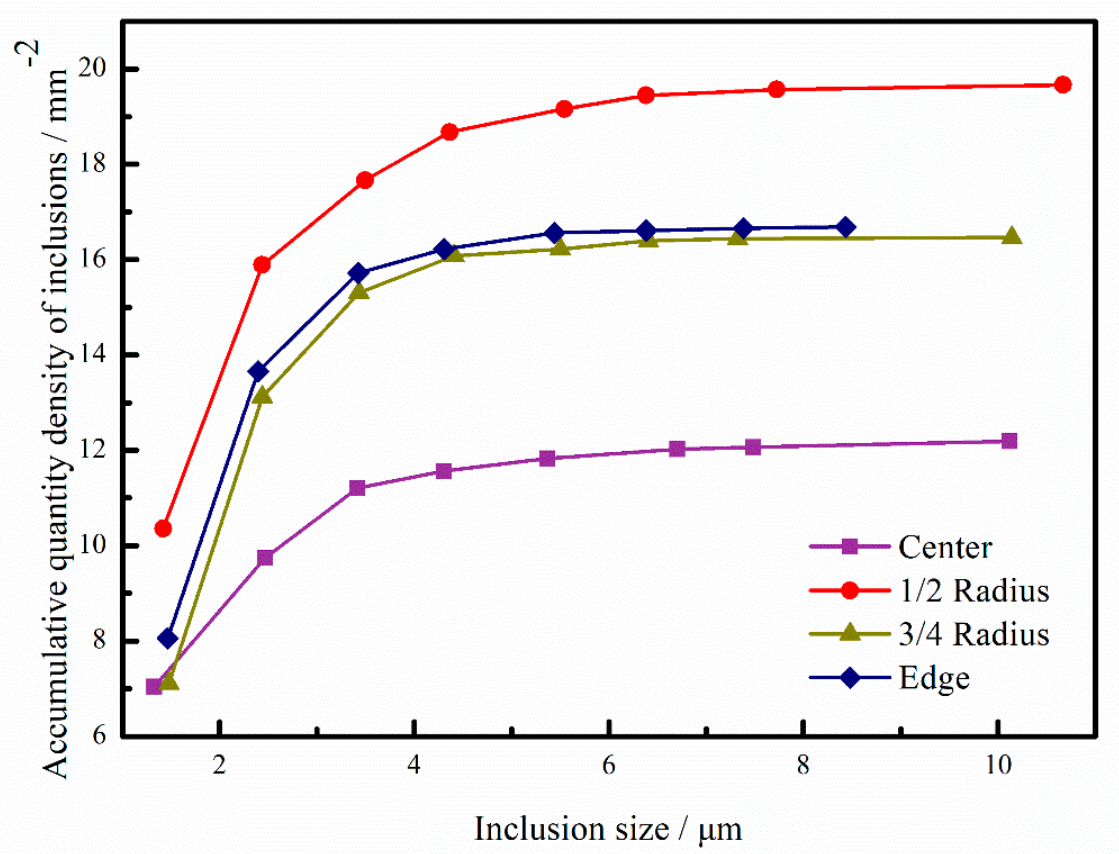

Figure 7. Accumulative density of different sizes of sulfide inclusions.

The machinability of gear steel is caused by a large amount of sulfide inclusions in the steel. Compared with oxide inclusions, the size distribution of sulfide inclusions is similar to the former, and their range is wider. As for the distribution of inclusions, the amount of sulfide inclusions in each position is much larger than that of oxide inclusions. Owing to the fact that the sulfide inclusions contained some composite inclusions of oxides and sulfides, it is well explained that the cumulative total oxygen content of the oxide inclusions is significantly lower than the total oxygen content measured by the infrared absorption method.

Based on the above analysis, inclusions with sizes above $10 \mu \mathrm{m}$ mainly exist in a band area from the center to the $1 / 2$ radius. Actually, the band with large sizes of inclusions is far from the working face of the gear, and that is also good for the fatigue life of the gear. So, it is critical to control both the sizes and distribution of inclusions on the section of the forging [24].

In summary, considering the distribution of total oxygen content, inclusion quantity distribution and size distribution of gear steel $18 \mathrm{CrNiMo} 7-6$ forging, the area from the $3 / 4$ radius to the edge with high cleanliness is more reasonable to be selected for the machining of the gear face.

\subsection{Relationship between Total Oxygen and Inclusions}

The accumulative oxygen content in oxide inclusions with different sizes can be calculated by Equations (1)-(4) [25-27] to estimate the contributions of oxides inclusions to the total oxygen in the steel. In these equations, DeHoff's formulas are expressed by Equations (1) and (2), the volume fraction of oxides can be obtained by Equation (3), and the oxygen content in oxide inclusions is described by Equation (4).

$$
\begin{gathered}
N_{\mathrm{v}}=\frac{2}{\pi} \cdot \frac{N_{a}}{\bar{d}}, \\
\frac{1}{\bar{d}}=\frac{1}{n} \sum \frac{1}{d_{i}{ }^{\prime}} \\
V=\frac{\pi}{6} \bar{d}^{3} \cdot N_{\mathrm{v}}, \\
{[O]_{\mathrm{ox}}=\left(\frac{\rho_{\mathrm{ox}}}{\rho_{\mathrm{Fe}}}\right) \cdot V \cdot(O)_{\mathrm{ox}},}
\end{gathered}
$$


where $N_{\mathrm{V}}$ is the number of oxide inclusions per unit volume in the specimen, in $\mathrm{m}^{-3} ; N_{\mathrm{a}}$ is the number density of oxide inclusions per unit area in the specimen, in $\mathrm{m}^{-2} ; d_{i}$ is the apparent particle size of the $i$-th oxide inclusions among $\mathrm{n}$ oxides, in $\mathrm{m} ; \bar{d}$ is the harmonic mean of oxide inclusions' particle size, in $\mathrm{m} ; \mathrm{V}$ is the volume fraction of oxide inclusions; $[O]_{\mathrm{ox}}$ is the oxygen content in oxide inclusions in the steel; $\rho_{\mathrm{ox}}$ is the density of oxide inclusions, in $\mathrm{kg} \cdot \mathrm{m}^{-3} ; \rho_{\mathrm{Fe}}$ is the density of the steel, in $\mathrm{kg} \cdot \mathrm{m}^{-3} ;(O)_{\mathrm{ox}}$ is the oxygen content of oxide inclusions.

Figure 8 shows the relationship between oxide sizes and the accumulative oxygen in oxides per unit volume. It was reported by [21] that the proportion of bound oxygen in oxides with diameters smaller than $5 \mu \mathrm{m}$ exceeded $80 \%$ of the total oxygen in Al-killed steel. Under the present results, the oxygen in oxide inclusions with sizes below $8 \mu \mathrm{m}$ occupies less than $13 \%$ of the total oxygen in the steel.

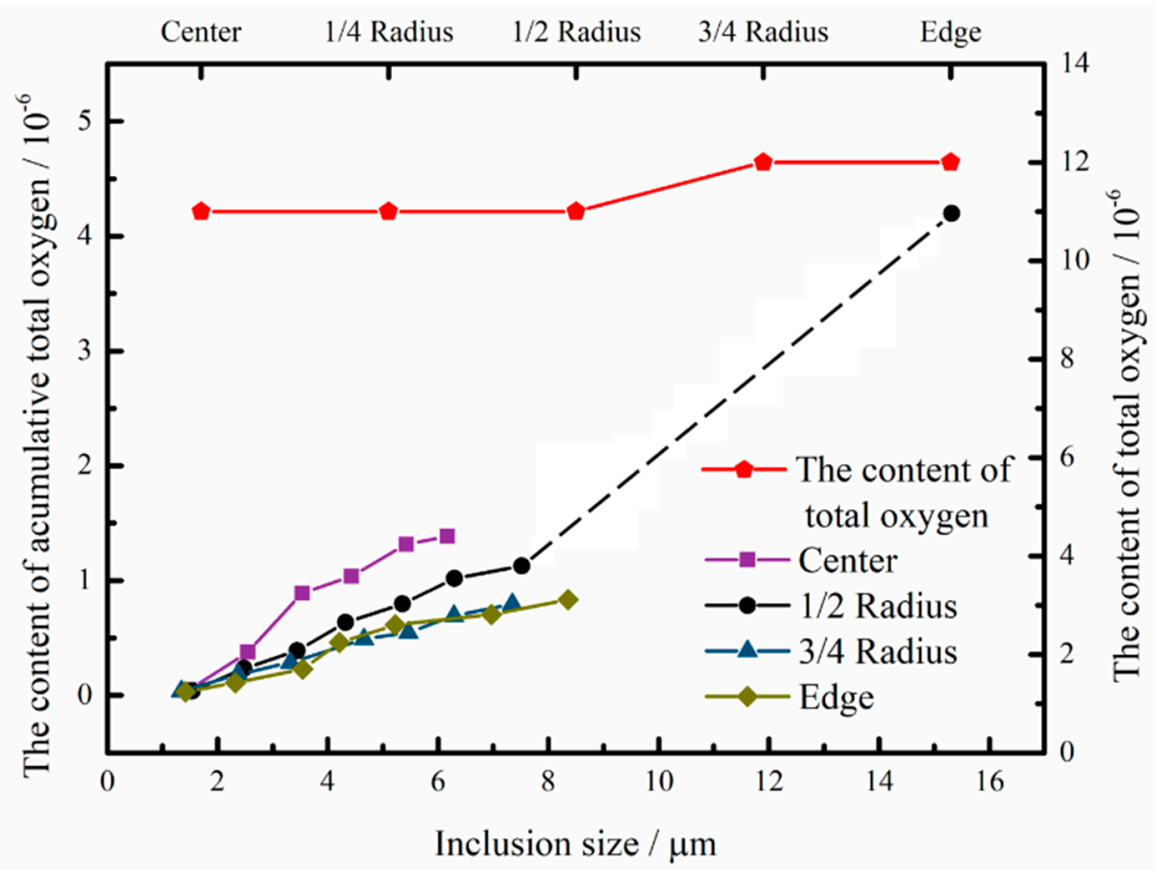

Figure 8. Relationship between oxide sizes and accumulative oxygen in oxides per unit volume.

The accumulative total oxygen content increases with increasing inclusion size when the size is less than $8 \mu \mathrm{m}$. The quantity of inclusions with a size less than $8 \mu \mathrm{m}$ accounts for more than $90 \%$, making a vital contribution to total oxygen. Except for the sharp increase in the oxygen content due to the large-sized inclusions appearing at the $1 / 2$ radius, the oxygen content increases steadily as the size of inclusions increases at other positions, and the cumulative oxygen content is stabilized at a fixed value.

In Al-deoxidization liquid steel, the dissolved oxygen content depends on the $\mathrm{Al}$ content. The reaction between $[\mathrm{Al}]$ and $[\mathrm{O}]$ can be expressed by

$$
\begin{gathered}
2[\mathrm{Al}]+3[\mathrm{O}]=\mathrm{Al}_{2} \mathrm{O}_{3}(\mathrm{~s}) \\
\Delta G^{\ominus}=-1218799+394.13 T
\end{gathered}
$$

Considering $f_{\mathrm{Al}}=f_{\mathrm{O}}=1$, and when $T=1873 \mathrm{~K}$, there are

$$
[\% A l][\% \mathrm{O}]^{1.5}=2.00 \times 10^{-7}
$$

In this steel, the $\mathrm{Al}$ content is $0.03 \%$, as showed in Table 1 . Thus, the dissolved oxygen content is $3.5 \mathrm{ppm}$, as calculated by Equation (7). 
The total oxygen content of gear steel $18 \mathrm{CrNiMo}-6$ forging is 11 to $12 \mathrm{ppm}$, with an average of $11.4 \mathrm{ppm}$.

Figure 9 describes the relationship among dissolved oxygen, bound oxygen in oxides, and bound oxygen in composite inclusions at different locations. It can be seen that a large proportion of oxygen exists in the composite inclusions, which means that a large proportion of oxides is wrapped by sulfides. Higher bound oxygen in oxides than that in composite inclusions at the location of the $1 / 2$ radius indicated that large oxides are difficult to be wrapped by sulfide.

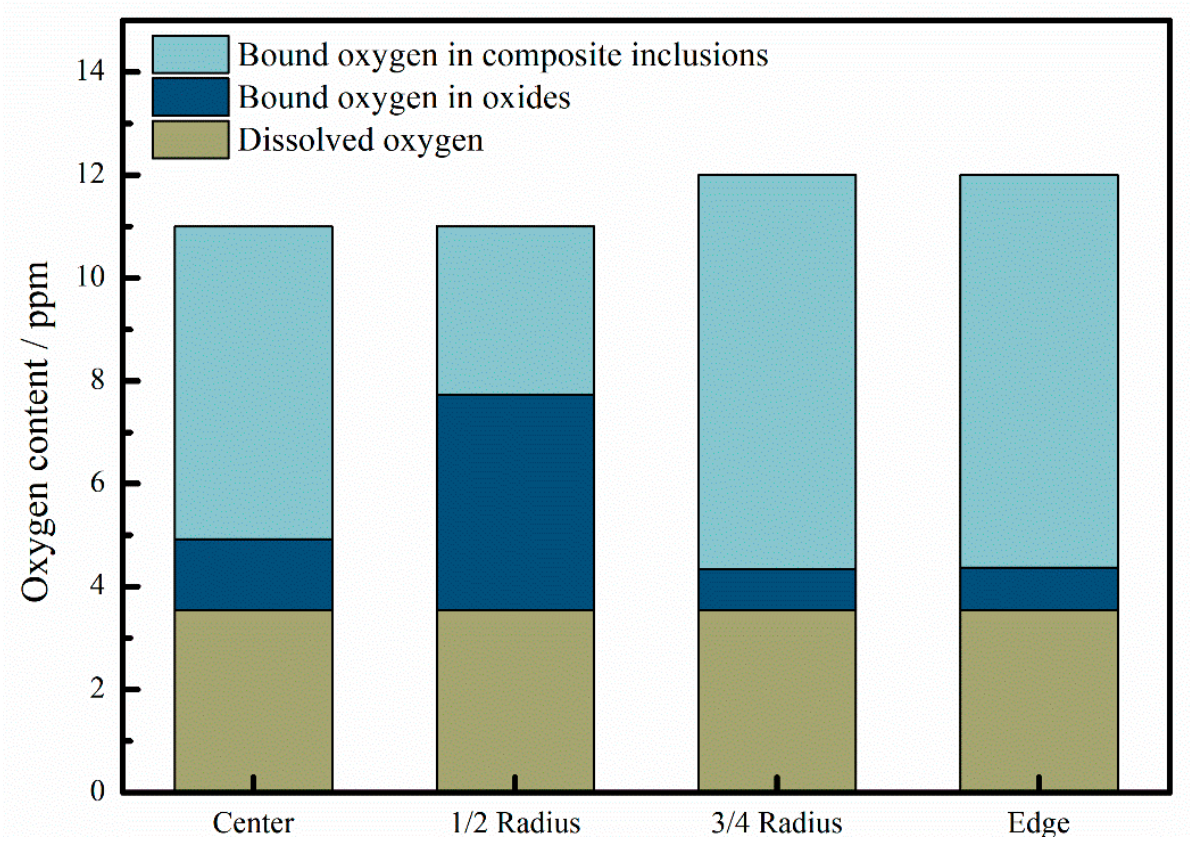

Figure 9. Relationship among dissolved oxygen, bound oxygen in oxides, and bound oxygen in composite inclusions at different locations.

Since the quantity and the size of single oxide inclusions in gear steel 18CrNiMo7-6 are small, the accumulative total oxygen content has a certain difference from the total oxygen content measured by the infrared absorption method, but the change in the oxygen content at the four positions is relatively stable. Therefore, the average value of the oxygen content can reflect the level of inclusions that are evenly distributed in the molten steel.

\subsection{Cyclic Fatigue Performance}

The S-N curve of fatigue tests for the material is shown in Figure 10. The S-N curve of fatigue cycles at the directions of the transverse and longitudinal specimens reaches $10^{9}$ when the loading stress is below 530 and $410 \mathrm{MPa}$, respectively, and the two types of fatigue specimens will fail when the loading stress is higher than the above values, respectively. 


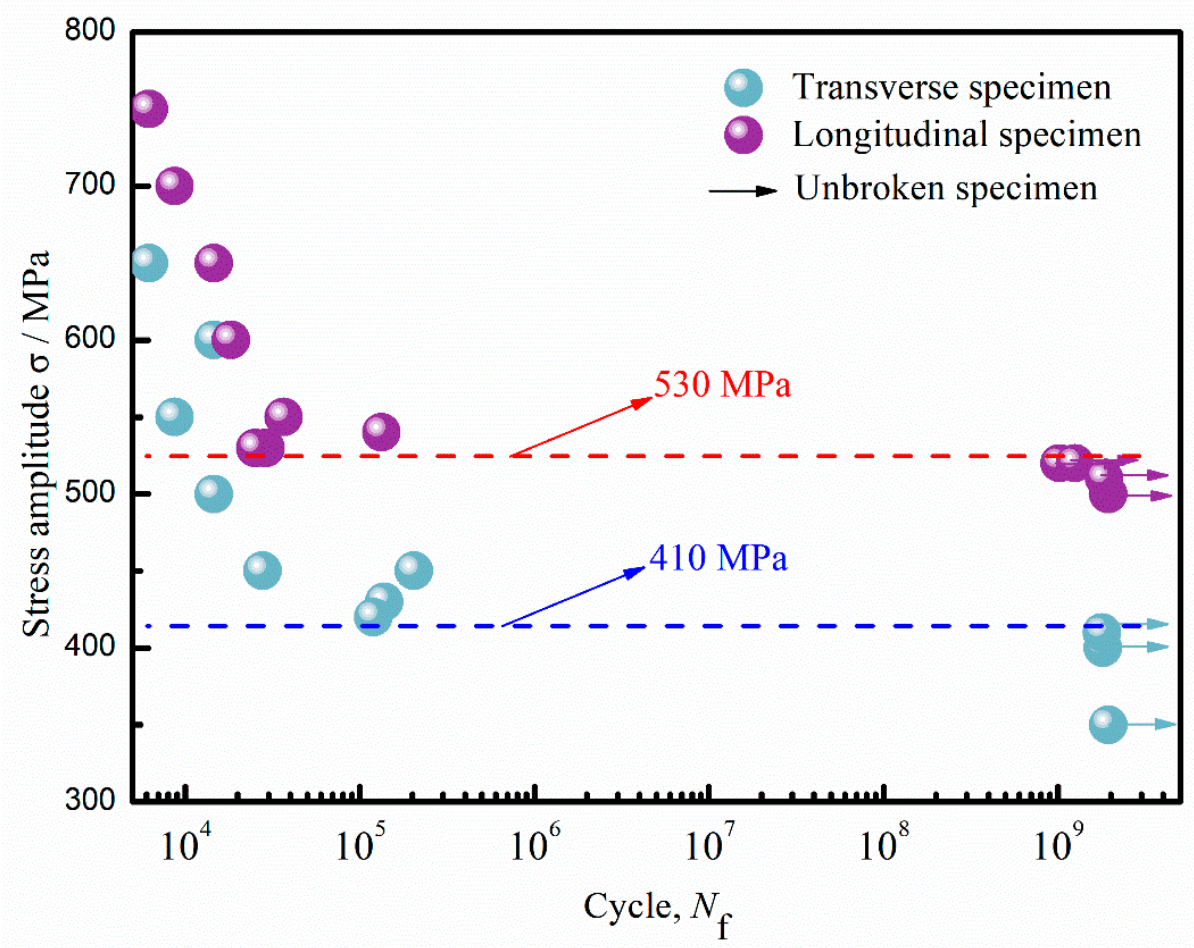

Figure 10. S-N curve of the internal crack initiation.

Combined with the fatigue test results, when the loading stress of the specimens is higher than the critical value, the specimens tend to fail, while if it is lower than the critical value, the fatigue cycle can reach more than $10^{9}$, which means the specimens possess good anti-fatigue characteristics.

Figure 11 shows the fracture morphologies of some specimens. As can be seen in the figure, some specimens were tested under a load higher than the critical value; as a result, fatigue failure occurs rapidly during the experiment, and the fatigue source has not been fully expanded due to the interruption of the fatigue test.

Among them, $\mathrm{Al}_{2} \mathrm{O}_{3}-\mathrm{CaO}$ composite inclusions are found in some fatigue sources as showed in Figure 11d. It has been pointed out [28] that fatigue fracture for $\mathrm{Al}_{2} \mathrm{O}_{3}-\mathrm{CaO}$ inclusions occurred at lower stress amplitudes than that for TiN or CaO-type inclusions, and no failure occurred for $\mathrm{Al}_{2} \mathrm{O}_{3}-\mathrm{CaO}$ inclusions when fatigue life was far beyond $10^{7}$ cycles, while TiN and CaO-type inclusions, fractures were still caused at nearly $10^{9}$. This indicates that the gear steel $18 \mathrm{CrNiMo} 7-6$ contained inclusions such as $\mathrm{Al}_{2} \mathrm{O}_{3}-\mathrm{CaO}$, which is prone to fatigue failure at a critical value due to the effect of $\mathrm{Al}_{2} \mathrm{O}_{3}-\mathrm{CaO}$ composite inclusions on the matrix. 

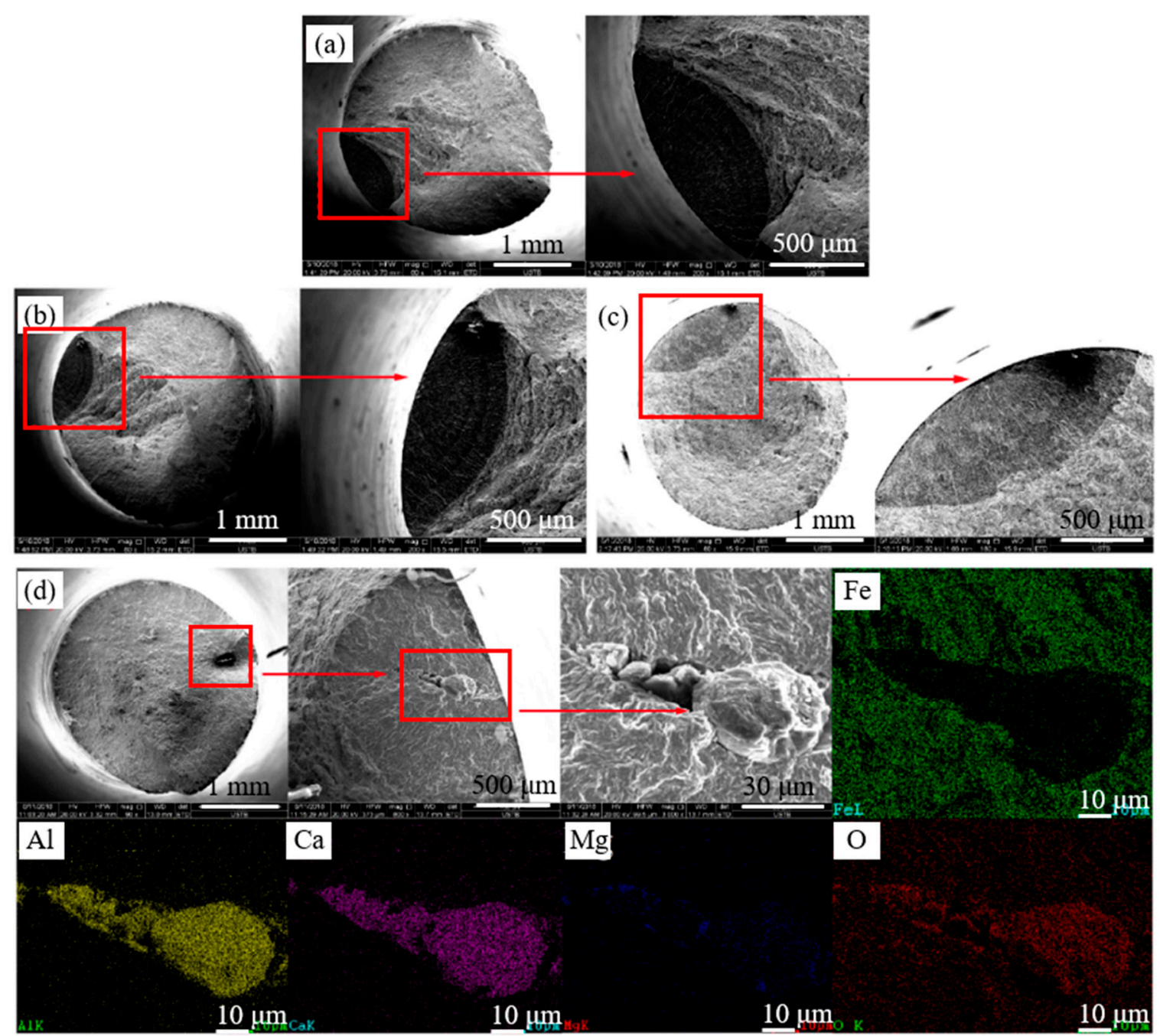

Figure 11. Fracture surfaces of the failed specimens, $(\mathbf{a}-\mathbf{c})$; and $\mathrm{Al}_{2} \mathrm{O}_{3}-\mathrm{CaO}$ inclusions in the fatigue source $(\mathbf{d})$.

In summary, different from the general fatigue test results, there is a critical value in the relationship between the fatigue life and the loading stress of $18 \mathrm{CrNiMo7-6}$ gear steel. The specimen will fail after the stress exceeds the critical value, and fatigue failure hardly occurs when the stress is below the critical value. Meanwhile, the gear steel $18 \mathrm{CrNiMo} 7-6$ contained inclusions such as $\mathrm{Al}_{2} \mathrm{O}_{3}-\mathrm{CaO}$, which is prone to fatigue failure after reaching the critical value.

\section{Conclusions}

(1) The main inclusions in the steel contain oxides and sulfides, where oxides contain $\mathrm{Al}_{2} \mathrm{O}_{3}-\mathrm{CaO}$, $\mathrm{Al}_{2} \mathrm{O}_{3}, \mathrm{Al}_{2} \mathrm{O}_{3}-\mathrm{MgO}$ and silicates, and sulfides contain $\mathrm{MnS}$ and composite inclusions of oxides and sulfides.

(2) The quantity density of inclusions per unit volume in gear steel $18 \mathrm{CrNiMo} 7-6$ decreases exponentially with increasing size, and the inclusions are mainly less than $8 \mu \mathrm{m}$. Oxide inclusions with a size less than $8 \mu \mathrm{m}$ account for more than $90 \%$, while sulfide inclusions with a size less than $8 \mu \mathrm{m}$ account for more than $85 \%$.

(3) As the size of inclusions increases, the accumulative total oxygen content increases significantly. The accumulative total oxygen content has a certain difference from the total oxygen content measured by the infrared absorption method, but the change in the oxygen content at the four positions is relatively stable, and there are a great deal of sulfide inclusions, including some 
composite inclusions of oxides and sulfides. As a result, the average value of the oxygen content can reflect the level of inclusions that were evenly distributed in the molten steel.

(4) Different from the general fatigue test results, there is a critical value in the relationship between the fatigue life and the loading stress of $18 \mathrm{CrNiMo} 7-6$ gear steel. The specimen will fail after the stress exceeds the critical value. However, fatigue failure hardly occurs when the stress is below the critical value. Meanwhile, the gear steel $18 \mathrm{CrNiMo7-6}$ contained inclusions such as $\mathrm{Al}_{2} \mathrm{O}_{3}-\mathrm{CaO}$, which is prone to fatigue failure.

Author Contributions: Data curation, M.W., P.G. and C.G.; writing—original draft preparation, M.W. and W.X.; writing - review and editing, W.X., M.W. and Y.-P.B.; supervision, Y.-P.B. All authors have read and agreed to the published version of the manuscript.

Funding: This research was funded by the National Natural Science Foundation of China (No. 51774031).

Acknowledgments: The authors wish to express their gratitude to the foundation for providing financial support.

Conflicts of Interest: The authors declare no conflict of interest.

\section{References}

1. Farfán, S.; Rubio-González, C.; Cervantes-Hernández, T.; Mesmacque, G. High cycle fatigue, low cycle fatigue and failure modes of a carburized steel. Int. J. Fatigue 2004, 26, 673-678. [CrossRef]

2. Mohammad, A.; Alahmari, M.A.; Moiduddin, K.; Mohammed, K.M.; Alomar, A.; Renganayagalu, K.R. Porous $\gamma$-TiAl structures fabricated by electron beam melting process. Metals 2016, 6, 25. [CrossRef]

3. Luo, C. Development and application of high strength automotive carburizing gear steels. Steelmaking 2006, 22, 56-59.

4. Yuta, I.; Kunikazu, T.; Kimihiro, N. Development of carburizing steel for innovation in parts manufacturing process. JFE Tech. Rep. 2018, 23, 36-42.

5. Manigandan, K.; Srivatsan, T.S. On the specific role of microstructure in governing cyclic fatigue, deformation, and fracture behavior of a high-strength alloy steel. JMEPEG 2015, 24, 2451-2463. [CrossRef]

6. Garrison, W.M. The effect of Toughness of a 0.4 Carbon Low Alloy Steel. Metall. Trans. 1986, 17A, 669-678. [CrossRef]

7. Tanaka, H.; Nishihara, R.; Miura, R.; Tsujino, R.; Kimura, T.; Nishi, T.; Imoto, T. Technology for cleaning of molten steel in tundish. ISIJ Int. 1994, 34, 868-875. [CrossRef]

8. Donzella, G.; Faccoli, M.; Mazzù, A.; Petrogalli, C.; Desimone, H. Influence of inclusion content on rolling contact fatigue in a gear steel: Experimental analysis and predictive modelling. Eng. Fract. Mech. 2011, 78, 2761-2774. [CrossRef]

9. Furuya, Y.; Abe, T.; Matsuoka, S. Inclusion-controlled fatigue properties of 1800 MPA-class spring steels. Metal. Mater. Trans. A 2004, 35, 3737-3744. [CrossRef]

10. Cho, J.W.; Emi, T.; Shibata, H.; Suzuki, M. Heat Transfer across mold flux film in mold during initial solidification in continuous casting of steel. ISIJ Int. 1998, 38, 834-842. [CrossRef]

11. An, J.; Wang, Z.; Li, R.; Li, T.; Ding, K.; Li, R. Cleanliness of automobile gear steel 8620RH. China Metal. 2016, 26, 33-37.

12. Dong, Y.; Jiang, Z.; Gong, W. Source analysis of inclusions in gear steel of $20 \mathrm{CrNiMoH}$. J. Mater. Metal. 2003, 2, 253-256.

13. Payandeh, Y.; Soltanieh, M. Oxide inclusions at different steps of steel production. J. Iron Steel Res. Int. 2007, 14, 39-46. [CrossRef]

14. Nordin, E.; Alfredsson, B. Experimental Investigation of Shot Peening on Case Hardened SS2506 Gear Steel. Exp. Tech. 2017, 41, 433-451. [CrossRef]

15. Qiao, X.; Sun, P. Quantitative study of Ca content and sulfide morphology in the free cutting steel. J. Huazhong Uni. Ofence Technol. 1995. [CrossRef]

16. Bao, Y.; Wang, M.; Jiang, W. A method for observing the three-dimensional morphologies of inclusions in steel. Int. J. Min. Metal. Mater. 2012, 19, 111-115. [CrossRef]

17. Yang, S.; Li, J.; Zhu, L.; Chen, Y.; Zhang, L. Status quo of research on $\mathrm{MgAl}_{2} \mathrm{O}_{4}$ spinel inclusion in steel and trend of its development. Steelmaking 2010, 26, 74-78. 
18. Deng, Z.; Zhu, M.; Zhong, B.; Gao, X. Effect of deoxidation methods on inclusions in steel. J. Univ. Sci. Technol. Beijing 2012, 34, 1256-1261.

19. Dong, W.; Ni, H.; Zhang, H.; Lv, Z.; Wu, Y. Control of magnesia-alumina spinel inclusions in the ultra-low-oxygen gear steel 28MnCr5. J. Iron Steel Res. 2015, 27, 14-18.

20. Hu, Q.; Zhao, J.; Zhu, S. On Formation and prevention of non-metallic inclusion of heavy forgings. J. Netshape Form. Eng. 2011, 3, 69-71.

21. Wakoh, M.; Sawai, T.; Mizoguchi, S. Effect of S content on the MnS precipitation in steel with oxide nuclei. ISIJ Int. 1996, 36, 1014-1021. [CrossRef]

22. Guo, B.; Bao, Y.; Wang, M.; Lin, L. Effects of $w(\mathrm{Ca}) / w(\mathrm{Al})$ on transformation of inclusions in the calcium treatment in 20Mn2 steel. Steelmaking 2015, 31, 36-44.

23. Gong, J.; Wang, Q. Thermodynamic analysis of calcium treatment on liquid steel. Steelmaking 2003, 19, 56-59.

24. Li, X.; Yang, M.; Zhou, X.; Guo, J. Torsion fatigue characteristics and crack propagation behavior of 15Cr14Co12Mo5Ni2 gear steel. Iron Steel 2017, 52, 84-91.

25. Wang, M.; Bao, Y.P.; Cui, H.; Wu, H.J.; Wu, W.S. The composition and morphology evolution of oxide inclusions in Ti-bearing ultra low-carbon steel melt refined in the RH process. ISIJ Int. 2010, 50, 1606-1611. [CrossRef]

26. Gu, C.; Wang, M.; Bao, Y.; Wang, F.; Lian, J. Quantitative analysis of inclusion engineering on the fatigue property improvement of bearing steel. Metals 2019, 9, 476. [CrossRef]

27. Xiao, W.; Wang, M.; Bao, Y. The research of low-oxygen control and oxygen behavior during RH process in silicon-deoxidization bearing steel. Metals 2019, 9, 812. [CrossRef]

28. Spriestersbach, D.; Grad, P.; Kerscher, E. Influence of different non-metallic inclusion types on the crack initiation in high-strength steels in the VHCF regime. Int. J. Fatigue 2014, 64, 114-120. [CrossRef]

(C) 2020 by the authors. Licensee MDPI, Basel, Switzerland. This article is an open access article distributed under the terms and conditions of the Creative Commons Attribution (CC BY) license (http://creativecommons.org/licenses/by/4.0/). 